\title{
Using GNSS Technologies for Research Features Vertical Movements of the Crust of Europe
}

\section{Introduction}

Dynamics of the lithosphere is one of the most important issues of geodynamics, and for many years it was the subject of geological and geophysical studies, based on different approaches, sometimes mutually exclusive ones. With the accumulation of data at various times there were different concepts of the origin of the modern configuration of the Earth's surface, the history of its development and the driving force of evolution. First, much of the data was obtained with the help of the geological methods that differ in the degree of detail and scope of covered Earth's surface.

Among the first observations that led to extensive discussion about the possible global movement of lithospheric plates, it was found the magnetic anomalies that extend along the mid-ocean ridges, which explains the tectonics plates apart (spreading) of the ocean floor, and periodic changes in the orientation of the global magnetic field [4].

Comparison of different data movements of the lithosphere for a long time made it possible to simulate quite rough overall picture of the dynamics of the Earth's surface, which was due to a variety of hypotheses about the driving forces of the observed processes. From the above data the information about velocity is kept only in the band structure of magnetic anomalies, and movement directions are determined from seismic observations and orientation transformational faults.

Studies of modern geodynamics Europe according to GNSS observations found a link between the heterogeneity of the structure of the western part of the Eurasian plate and its division into blocks of relative mobility, which are manifested in vertical crustal movements [1]. In the vertical movements of permanent stations was found expression coseismic and post seismic deformation. These questions explored foreign scientists - see work $[2,3]$. According to the international project CERGOP the results of GNSS observations at 60 permanent stations from the period 1994 to 2005 was drawn

\footnotetext{
* National University "Lviv Polytechnic", Lviv, Ukraine
} 
map of vertical crustal movements in Central and Western Europe [3]. Comparison of this map with epicenters of earthquakes and faults outside major lithospheric plates found that most modern Eurasian blocks are relatively rigid and the transfer of stress from subduction zones to zones of conflict their margins can be deformed that is easy to find in the results of observations on permanent stations.

Thus, the problem of the study of the dynamics of modern neotectonic vertical crustal movements is relevant as studying and analyzing the results of observations of permanent GNSS stations can explore the spatio-temporal evolution of deformation fields and their features. However, previous studies have found a direct link between anomalous zones of vertical motions and tectonic structure.

\section{Methods}

With the advent of permanent GNSS networks it is possible to monitor crustal deformation processes and search their relationships with tectonic structure.

In this article, in order to study vertical crustal movements in Europe, was held a complex of research. The database of permanent stations was processed at which observations were performed at least three years. Permanent stations are located throughout the European continent. In the next step were selected the time series of stations that had continuous series of observations in furthering 2000-2011 without jumps in high-altitude position. Permanent stations that have gaps in the ranks of the observations were taken up to six months in the study, but during the break was adopted the average value of the velocity of vertical crustal movements for the previous and next years. Some stations for the period of observation had instantaneous jumps in high-altitude position, which was associated with the change of antenna on them. In the time series of these stations was introduced appropriate adjustment for changes in antenna height. As a result of filtration were selected 196 stations.

For the original data in the study of geodynamics of Europe we used the results of permanent stations represented on the web page of SOPAC (Scripps orbit and permanent array center) [6] and on the website of NGL (Nevada Geodetic Laboratory) [5]. SOPAC is one of the centers of satellite data, which has a database of the most permanent stations of the world. Basic scientific SOPAC function is to maintain high precision of geodetic and geophysical measurements using the Global Positioning System (GPS) of satellites, in particular for the study of earthquakes, tectonic plate motions, crustal deformation and meteorological processes. Geodetic Laboratory in Nevada (NGL) holds the research in the field of space geodesy to solve the scientific problems that have both regional and global significance. Using GPS the laboratory studies the area of modern tectonic activity of the lithosphere. To study the seismic activity of the European continent was processed database of earthquakes of national seismic center of the USA.

For selected permanent stations were calculated annual values of absolute velocity of vertical crustal movements and mean square error of their determination. 
To set the annual regional rate of vertical movement, it was determined the average absolute rate of vertical movement of all permanent stations that subtract the values of absolute vertical movement velocity of each permanent station during the year:

$$
V_{i}^{\mathrm{reg}}=V_{i}^{\mathrm{abs}}-\frac{\sum_{j=1}^{n} V_{j}^{\mathrm{abs}}}{n}, i=1, \ldots, n
$$

where:

$V_{i}^{a b s}$ - absolute rate of vertical movement of i permanent station

$n$ - total number of stations selected for study.

According to equation (1) was calculated the regional rate of vertical movement of permanent stations. We got mean square error for determining an absolute vertical movement velocity, which is in the range of $3 \mathrm{~mm} /$ year. Summarizing the analysis of the research results were compiled Table 1 of extreme annual absolute and regional rates of vertical movement of permanent stations.

In columns 2 and 3 of Table 1 are indicated the extreme values of the absolute velocity of vertical movements (lifting and lowering) the crust from 2000 to 2011 and years. The sign "-" before the number indicates subsidence, and "+" sign to raise of permanent station. In columns 4 and 5 are the average values of each year of study. The sixth column contains values averaged vertical velocities of the permanent stations during the year, columns 7-10 listed regional significance.

Table 1. Absolute and regional rate of vertical movement stations in Europe (mm/year)

\begin{tabular}{|c|c|c|c|c|c|c|c|c|r||}
\hline \multirow{2}{*}{ Years } & \multicolumn{5}{|c|}{ Absolute } & \multicolumn{3}{c||}{ Regional } \\
\cline { 2 - 10 } & $\max$ & $\min$ & Aver. (+) & Aver. (-) & $\begin{array}{c}\text { average } \\
\text { total }\end{array}$ & $\max$ & $\min$ & Aver. (+) & Aver. (-) \\
\hline 1 & 2 & 3 & 4 & 5 & 6 & 7 & 8 & 9 & 10 \\
\hline \hline 2000 & 20.55 & -11.47 & -4.12 & 7.91 & 3.90 & 16.65 & -15.37 & -6.05 & 6.20 \\
\hline 2001 & 15.43 & -9.85 & -3.42 & 4.81 & 0.53 & 15.90 & -10.38 & -3.69 & 4.69 \\
\hline 2002 & 16.43 & -24.19 & -5.65 & 4.50 & -2.08 & 18.51 & -22.12 & -4.90 & 4.97 \\
\hline 2003 & 20.39 & -18.77 & -3.54 & 5.98 & 4.52 & 15.86 & -23.29 & -3.64 & 3.94 \\
\hline 2004 & 20.97 & -12.18 & -3.06 & 6.09 & 5.47 & 15.50 & -17.65 & -2.73 & 3.09 \\
\hline 2005 & 18.35 & -23.84 & -4.03 & 5.82 & 2.30 & 16.06 & -26.13 & -4.60 & 5.16 \\
\hline 2006 & 19.54 & -22.56 & -4.30 & 8.17 & 7.44 & 12.10 & -29.99 & -4.41 & 4.61 \\
\hline 2007 & 26.53 & -20.58 & -3.88 & 5.32 & -0.75 & 27.28 & -19.83 & -3.49 & 5.19 \\
\hline 2008 & 16.55 & -15.21 & -3.18 & 5.78 & 3.52 & 13.03 & -18.72 & -4.24 & 4.24 \\
\hline 2009 & 18.55 & -6.84 & -2.25 & 6.85 & 5.63 & 12.92 & -12.46 & -3.98 & 3.60 \\
\hline 2010 & 24.62 & -16.27 & -3.55 & 5.24 & 3.71 & 20.90 & -19.98 & -3.38 & 5.39 \\
\hline 2011 & 18.70 & -21.55 & -4.76 & 5.03 & 1.88 & 16.82 & -23.43 & -4.76 & 4.41 \\
\hline
\end{tabular}


On the basis of the calculations were drawn maps of the distribution of annual absolute vertical movements in Europe each year (Fig. 1).

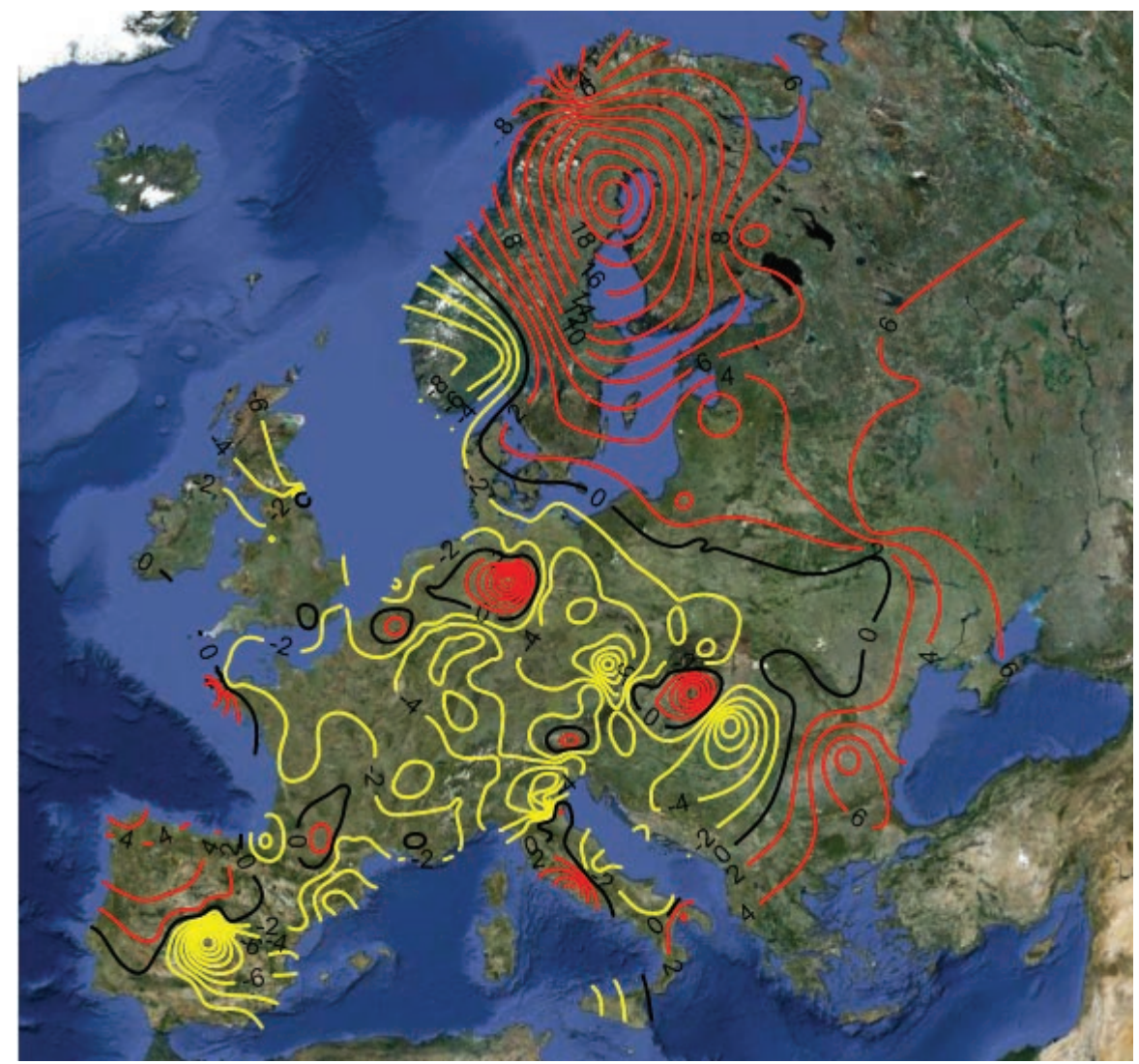

Fig. 1. Example of map of annual distribution of absolute vertical crustal movements according to the GNSS-stations in 2007

In the process of study, using Delaunay triangulation, the area of Europe was divided into triangles at the vertices of which are permanent station. After processing the data base of annual earthquake epicenters of seismic vibrations were sorted within each year epicenters of earthquakes selected triangles. For these triangles designed their integrated high-rise biasing:

$$
\Delta H_{\mathrm{int}}=S \frac{\sum\left|V_{i}\right|}{3}
$$

where:

$S$ - area of the triangle,

$\left|V_{i}\right|-$ absolute velocity of the crust.

Graphically, these parameters are shown in Figure 2. 


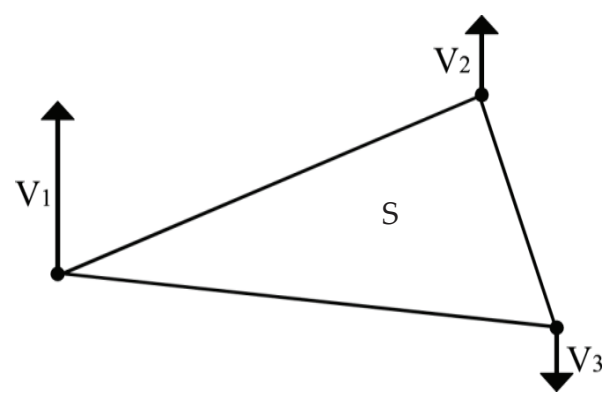

Fig. 2. Vectors displacement peaks elementary triangles

The ellipses scattering earthquake epicenters have been constructed for all triangles [7]. Semi-major axis of the ellipse of dispersion magnitude earthquake epicenters summarizes mainly by strong earthquakes with magnitude as small axis by weaker earthquakes that make up the background seismic study area (Fig. 3).

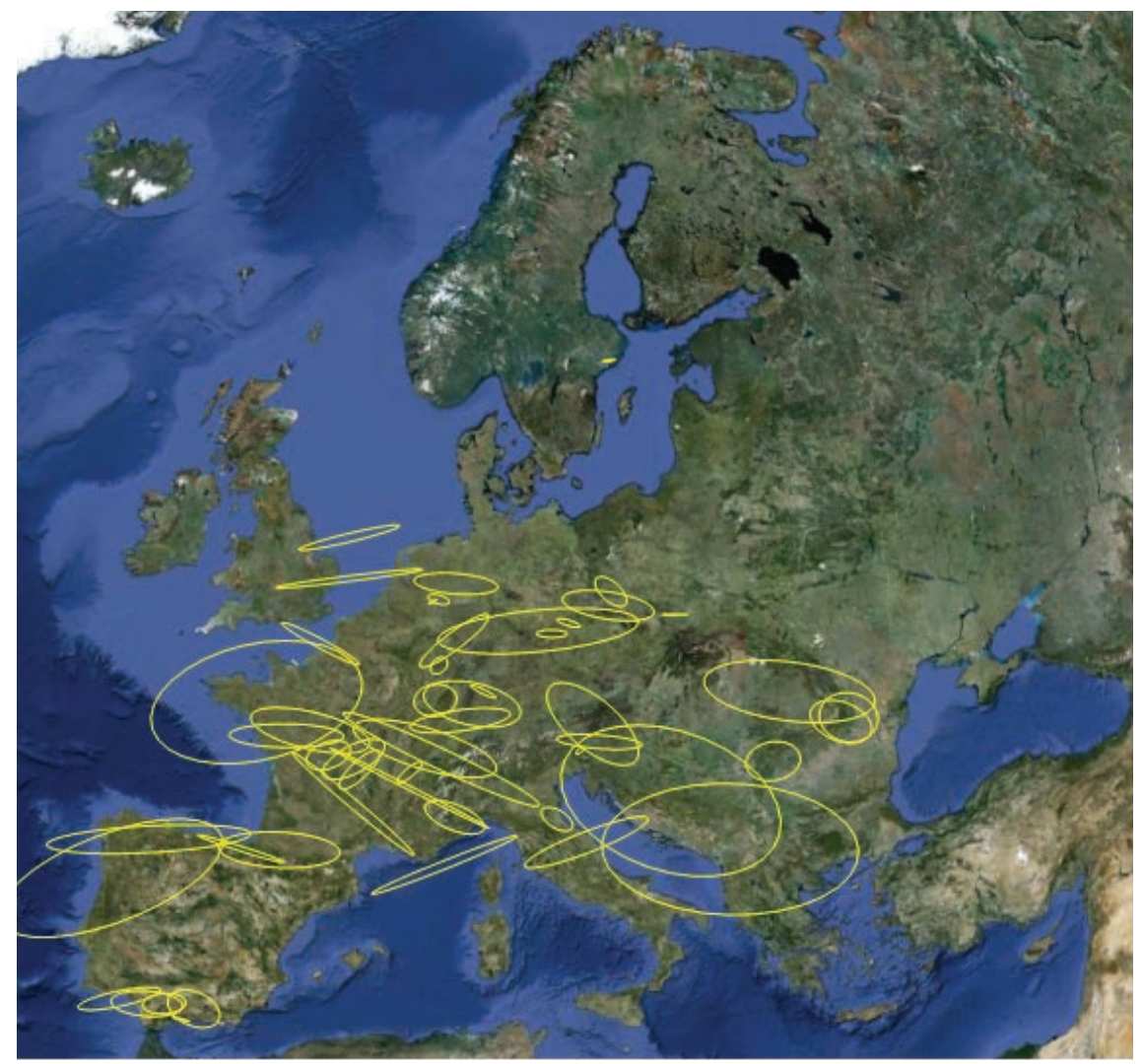

Fig. 3. Map of the dispersion ellipses of earthquakes in 2007 
Based on the study of two databases it was established the correlation between low semi axis ellipse of dispersion and displacement integral [7]. Figure 4 - dedicated area for which the correlation is in the range $0.6-0.9$. For the rest of the correlation is absent.

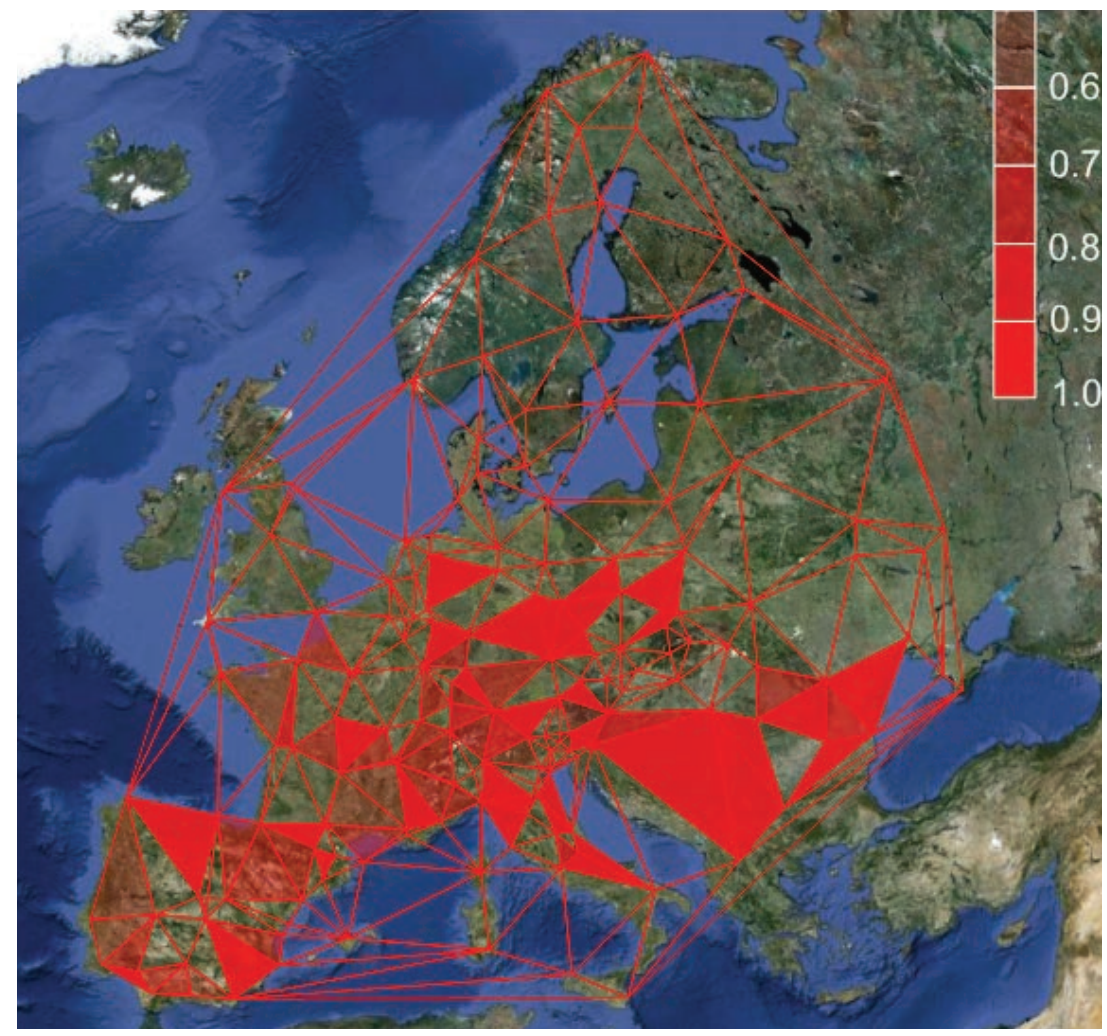

Fig. 4. The area with a high degree of correlation

\section{Summary and Conclusions}

The research period is 12 years and for the study of tectonic movements it is rather short period of time. Based on these studies it is impossible to make accurate predictions of tectonic movements, but from the created maps of the distribution of annual absolute vertical crustal movements and a comparative analysis of their seismic manifestations in Europe we can draw some conclusions:

1. The database of 196 Europe's permanent stations on which permanent observations during 2000-2011 were held and modern velocities of vertical crustal movements are calculated. 
2. The maximum and minimum total amplitudes of absolute velocities of vertical crustal movements are established.

3. The base map of distribution of annual absolute velocities of vertical movements Europe's territory is made.

4. The ellipses of scattering magnitude epicenters of earthquakes on Europe territory are built.

5. According to the definition of the Earth's surface deformation rates in Europe and the observations of seismic stations (based on the processing of information for the period from 2000 to 2011) found a correlation in the range (0.6-0.9), between the low semi axis ellipse of dispersion magnitude earthquake epicenters (formed by weak earthquakes) and integrated highaltitude offset. Highlight an area with a high level of correlation which coincides with a seismically active and mountainous area of Europe. This indicates that there is a relationship between vertical motion and seismic activity.

\section{References}

[1] Bennett R.A., Hreinsdóttir S.: Constraints on vertical crustal motion for long baselines in the central Mediterranean region using continuous GPS. Earth and Planetary Science Letters, vol. 257, no. 3-4, 2007, pp. 419-434.

[2] Calais E., Nocquet J.-M., Jouanne F., Tardy M.: Current strain regime in the Western Alps from continuous Global Positioning System measurements, 19962001. Geology, vol. 30, no. 3, 2002, pp. 651-654.

[3] Caporali A., Aichhorn C., Becker M. et al.: Geokinematics of Central Europe: New insights from the CERGOP-2/Environment Project. Journal of Geodynamics, vol. 45, issue 4, 2008, pp. 246-256.

[4] Gatinskiy Yu.G., Rundkvist D.V.: Geodinamika Yevrazii - tektonika plit i tektonika blokov. Geotektonika, no. 1, 2004, pp. 3-20.

[5] Nevada Geodetic Laboratory, [on-line:] http://geodesy.unr.edu [access: January, 2014].

[6] Scripps orbit and permanent array center, [on-line:] http://sopac.ucsd.edu [access: January, 2014].

[7] Tretyak K., Serant O., Smirnova O. Zv'yazok mizh horyzontal'nymy deformatsiyamy zemnoyi poverkhni ta seysmichnoyu aktyonistyu Tsentral'noyi Yevropy. Zb. nauk. pr. „Suchasni dosyahnennya heodezychnoyi nauky ta vyrobnytstva", L'vivs'ka politekhnika, L'viv, vypusk 1 (15), 2008, pp. 74-81. 